Dinamika Kesehatan Jurnal Kebidanan dan Keperawatan Vol 10 No. 1 Juli 2019 (ISSN: 2086-3454 EISSN: 2549-4058)

url: http://ojs.dinamikakesehatan.unism.ac.id DOI : https://doi.org/10.33859/dksm.v10i1

Pemanfaatan Teknologi Informasi Berbasis Internet Terhadap Perkembangan Home Care di Indonesia

\title{
Pemanfaatan Teknologi Informasi Berbasis Internet Terhadap Perkembangan Home Care Di Indonesia
}

\author{
Lola Illona Elfani Kausar1, Sukihananto2 \\ 1Mahasiswa Magister Keperawatan Komunitas, Fakultas Ilmu Keperawatan, \\ Universitas Indonesia, Depok \\ 2Dosen Keperawatan Komunitas dan Keperawatan Gerontik, Fakultas Ilmu Keperawatan, \\ Universitas Indonesia, Depok \\ *correspondence author: E-mail: 1ola.illona@ui.ac.id
}

DOI: https://doi.org/10.33859/dksm.v10i1.331

Abstrak
Latar Belakang : Masalah kesehatan di Indonesia masih cukup banyak, salah satunya adalah
penyakit tidak menular yang memerlukan perawatan lama dirumah. Kondisi geografis Indonesia yang
terdiri dari kepulauan menjadi hambatan bagi pelayanan keperawatan terhadap kondisi ini
dikarenakan permasalahan akses. Teknologi informasi berbasis internet seperti telehealth atau
mhealth sangat tepat digunakan untuk memecahkan permasalahan ini. Pemanfaatan telehealth atau
mhealth pada tatanan pelayanan keperawatan seperti home care dapat menghilangkan permasalahan
jarak antara perawat dan pasien. Pelayanan keperawatan dapat diberikan dalam jarak jauh berupa
videoteleconference ataupun pelayanan keperawatan lainnya seperti pendidikan kesehatan.
Tujuan: penelitian Bertujuan untuk mendeskripsikan pemanfaatan teknologi informasi berbasis
internet pada layanan home care keperawatan.
Metode: Penelitian ini menggunakan Metode literature review sesuai dengan topik pembahasan.
Teknologi informasi berbasis internet sangat perlu dikembangkan lebih lanjut dalam home care
keperawatan dikarenakan sangat membantu dalam proses peningkatan kesehatan pasien. Dukungan
dari pemerintah terkait infrastruktur dapat menjadi peluang bagi dunia keperawatan.
Kata kunci: home care, telehealth, mhealth, nursing informatics


Background:Health problems in Indonesia are still quite a lot, one of which is non-communicable diseases that require long-term care at home. The geographical condition of Indonesia which consists of islands is an obstacle to nursing services for this condition due to problems of access. Internetbased information technology such as telehealth or mhealth is very suitable to be used to solve this problem. The use of telehealth or mhealth in the nursing care order such as home care can eliminate the problem of distance between nurses and patients. Nursing services can be provided remotely in the form of videoteleconference or other nursing services such as health education.

Aim:The purpose of this study is to describe the use of internet-based information technology in home care.

Method: The method used is the literature review according to the topic of discussion. Internet-based information technology really needs to be further developed in home care because it is very helpful in the process of improving patient health. Support from the government regarding infrastructure can be an opportunity for the world of nursing.

Keywords: home care, telehealth, mhealth, nursing informatics

\section{Pendahuluan}

Angka morbiditas di Indonesia masih sangat tinggi dan terus mengalami peningkatan, salah satunya seperti penyakit yang bersifat kronis dan memerlukan perawatan yang lama seperti penyakit tidak menular (PTM) (Prasetyo, Djauhari and Wardojo, 2016). Berdasarkan RISKESDAS (Riset Kesehatan Dasar) tahun 2013, kejadian penyakit tidak menular seperti hipertensi berjumlah $25,8 \%$, stroke $12,1 \%$, dan Diabetes mellitus 2,1\% (RISKESDAS, 2013). Penyakit yang memerlukan perawatan lama pada saat ini menimbulkan tantangan bagi dunia keperawatan untuk meningkatkan penyedia layanan keperawatan yang berkelanjutan. Perawatan yang berkelanjutan dalam hal ini adalah perawatan transisi, yaitu perawatan yang berfungsi untuk memanajemen pasien ketika dirumah sehingga proses perawatan tetap kontinuitas (Lestari and Subardiah, 2017).

Homecare adalah suatu bentuk layanan keperawatan dirumah yang berkesinambungan dan komprehensif yang diberikan kepada pasien maupun keluarga pasien yang bertujuan untuk memulihkan, mempertahankan dan 
Dinamika Kesehatan Jurnal Kebidanan dan Keperawatan Vol 10 No. 1 Juli 2019 (ISSN: 2086-3454 EISSN: 2549-4058)

url: http://ojs.dinamikakesehatan.unism.ac.id DOI : https://doi.org/10.33859/dksm.v10i1

Pemanfaatan Teknologi Informasi Berbasis Internet Terhadap Perkembangan Home Care di Indonesia

meningkatkan $\quad$ kesehatan, menjadi semakin efektif dan efisien (cepat dan

mengoptimalkan kemandirian pasca tepat) (Nurwahidin, Lestari and Raharjo, perawatan dirumah sakit. Keterbatasan 2016). Berdasarkan hasil survey, penggunaan masyarakat dalam pembiayaan pelayanan internet masyarakat Indonesia terus kesehatan pada kasus-kasus penyakit yang mengalami peningkatan yaitu 143,26 juta jiwa memerlukan perawatan lama dirumah sakit berdampak pada meningkatnya kebutuhan masyarakat akan homecare, misalnya pada pasien pasca stroke yang mengalami kelumpuhan dan memerlukan perawatan lebih lanjut yang tentunya memerlukan waktu yang cukup lama dan biaya yang cukup besar apabila dirawat di rumah sakit. Selain itu banyak pasien merasakan bahwa perawatan dilingkungan rumah sendiri dirasa lebih mempercepat kesembuhan dikarenakan lebih nyaman dan lebih leluasa dibandingkan dirumah sakit yang terikat dengan aturanaturan (Prasetyo, Djauhari and Wardojo, 2016).

Saat ini teknologi informasi semakin berkembang pesat, khususnya teknologi informasi berbasis internet yang memiliki dampak positif terhadap banyak aspek dalam berbagai bidang, sehingga aktivitas kerja atau 54,7\% pada tahun 2017 (Buletin APJII, 2018). Hal ini sangat memungkinkan untuk penerapan home care dengan teknologi informasi berbasis internet di Indonesia seperti telehealth ataupun mobile health. Telehealth adalah pelayanan kesehatan yang menggunakan layanan elektronik untuk mendukung pelayanan yang diberikan kepada pasien, seperti perawatan, edukasi kesehatan ataupun pemantauan kesehatan jarak jauh yang memiliki azas untuk ditaati agar menjaga kualitas layanan yaitu aman, efektif, berpusat pada pasien, tepat waktu, efisien dan adil (Lestari and Subardiah, 2017).

Berdasarkan literature review yang dilakukan Istifada pada tahun 2017 tentang pemanfaatan telehealth pada home care, data untuk pengguna aplikasi telehealth sebanyak $81 \%$ di Kanada (2007), 74\% di Amerika (2013) (Istifada, 2017). Banyaknya pasien 
Dinamika Kesehatan Jurnal Kebidanan dan Keperawatan Vol 10 No. 1 Juli 2019 (ISSN: 2086-3454 EISSN: 2549-4058)

url: http://ojs.dinamikakesehatan.unism.ac.id DOI : https://doi.org/10.33859/dksm.v10i1

Pemanfaatan Teknologi Informasi Berbasis Internet Terhadap Perkembangan Home Care di Indonesia

yang memilih menggunakan telehealth dalam

perawatannya dirumah (homecare)

dikarenakan banyaknya manfaat yang

dirasakan seperti lebih hematnya biaya yang

dikeluarkan karena lama rawat yang singkat di

rumah sakit, berkurangnya biaya transportasi

ke fasilitas kesehatan (rumah sakit) yang di

Indonesia jaraknya cukup jauh yaitu rata-rata

hingga memakan waktu 60 menit

(RISKESDAS, 2013; Lestari and Subardiah, 2017).

Berdasarkan data di atas, diharapkan

dengan home care yang berbasis teknologi informasi internet dunia keperawatan mampu meningkatkan kontribusi dalam mengoptimalkan kesehatan masyarakat luas, sehingga dalam tulisan ini, penulis ingin mengeksplorasi bagaimana pemanfaatan teknologi informasi berbasis internet terhadap perkembangan home care khususnya di Indonesia, dan apa saja hambatan dan tantangan yang ada dalam penerapan teknologi informasi berbasis internet pada home care, serta apakah aplikasi berbasis internet yang diterapkan pada home care di luar negeri dapat di terapkan di Indonesia.

\section{Metode}

Penelitian ini menggunakan metode literature review dengan menelaah tigabelas artikel yang berasal dari jurnal nasional dan internasional terkait penerapan teknologi informasi berbasis internet dalam perawatan berkesinamabungan pasien (home care). Berikut adalah artikelartikel yang dianalisis sesuai dengan tema penelitian: 
Dinamika Kesehatan Jurnal Kebidanan dan Keperawatan Vol 10 No. 1 Juli 2019 (ISSN: 2086-3454 EISSN: 2549-4058)

url: http://ojs.dinamikakesehatan.unism.ac.id DOI : https://doi.org/10.33859/dksm.v10i1

Pemanfaatan Teknologi Informasi Berbasis Internet Terhadap Perkembangan Home Care di Indonesia

Tabel 1. Daftar Literatur yang dilakukan Telaah

\begin{tabular}{|c|c|c|c|c|}
\hline No. & Penulis & Judul & Metode & Hasil \\
\hline 1. & $\begin{array}{l}\text { Akhmad Hadi } \begin{array}{r}\text { Sutrisno, } \\
\text { Edhy Sutanta, Uning } \\
\text { Lestari }\end{array} \\
\end{array}$ & $\begin{array}{l}\text { Aplikasi mobile untuk layanan } \\
\text { perawatan medis di rumah sakit } \\
\text { (studi kasus di rumah sakit } \\
\text { bhayangkara polda DIY) }\end{array}$ & $\begin{array}{l}\text { Deskriptif sebuah } \\
\text { aplikasi }\end{array}$ & $\begin{array}{l}\text { TI sangat membantu } \\
\text { dalam pelayanan } \\
\text { keperawatan yang } \\
\text { perlu untuk terus } \\
\text { dikembangkan }\end{array}$ \\
\hline 2. & $\begin{array}{lrr}\text { Budi } & \text { Wiweko, } & \text { Aulia } \\
\text { Zesario, } & \text { Prince } & \text { Gusti } \\
\text { Agung } & & \end{array}$ & $\begin{array}{l}\text { Overview the development of } \\
\text { tele health and mobile helath } \\
\text { application in Indonesia }\end{array}$ & Literature Review & $\begin{array}{lr}\text { Telehealth } & \text { di } \\
\text { Indonesia saat ini } \\
\text { masih } & \text { bersifat } \\
\text { kuratif } & \text { yang } \\
\text { dilaksanakan } & \text { oleh } \\
\text { dokter } & \end{array}$ \\
\hline 3. & $\begin{array}{l}\text { Christina A. Olson, John F. } \\
\text { Thomas }\end{array}$ & $\begin{array}{l}\text { Telehealth: No longer an idea the } \\
\text { future }\end{array}$ & $\begin{array}{l}\text { Evidance-based } \\
\text { research }\end{array}$ & $\begin{array}{l}\text { Telehealth sangat } \\
\text { membantu dalam } \\
\text { proses perawatan } \\
\text { pasien dirumah, } \\
\text { yang perlu terus } \\
\text { dikembangkan agar } \\
\text { keraguan sebagian } \\
\text { masyarakat dalam } \\
\text { pemanfaatannya } \\
\text { dapat teratasi }\end{array}$ \\
\hline 4. & Francisca Cisneros Farrar & $\begin{array}{l}\text { Transforming home health } \\
\text { nursng with telehealth } \\
\text { technology }\end{array}$ & $\begin{array}{l}\text { Evidance-based } \\
\text { research }\end{array}$ & $\begin{array}{l}\text { Telehealth mampu } \\
\text { diaplikasikan dalam } \\
\text { keperawatan jiwa } \\
\text { (mental) dalam } \\
\text { meningkatkan } \\
\begin{array}{l}\text { kualitas asuhan } \\
\text { keperawatan bagi } \\
\text { pasien }\end{array}\end{array}$ \\
\hline 5. & $\begin{array}{l}\text { Grace O. Daniel, Modupe } \\
\text { O. Oyetunde }\end{array}$ & $\begin{array}{l}\text { Nursing informatics: A key to } \\
\text { improving nursing practice in } \\
\text { Nigeria }\end{array}$ & $\begin{array}{l}\text { Evidance-based } \\
\text { research }\end{array}$ & $\begin{array}{l}\text { Perkembangan } \\
\text { dunia keperawatan } \\
\text { harus dibarengi } \\
\text { dengan } \\
\text { perkembangan } \\
\text { nursing informatics } \\
\text { agar pelayanan } \\
\text { keperawatan yang } \\
\text { diberikan } \\
\text { berkualitas }\end{array}$ \\
\hline 6. & $\begin{array}{l}\text { Lucy Sitton-Kent, Catriona } \\
\text { Humphreys, Phillip Miller }\end{array}$ & $\begin{array}{l}\text { Supporting the spread of health } \\
\text { technologu in community } \\
\text { services }\end{array}$ & $\begin{array}{l}\text { Evidance-based } \\
\text { research }\end{array}$ & $\begin{array}{l}\text { Banyak manfaat dari } \\
\text { pelayanan kesehatan } \\
\text { berbasis TI, tetapi } \\
\text { masih perlu } \\
\text { dibuktikan lebih } \\
\text { lanjut kemungkinan } \\
\text { dampak negatif yang } \\
\text { dapat timbul }\end{array}$ \\
\hline 7. & $\begin{array}{l}\text { Peter Leijdekkers, Valerie } \\
\text { Gay, Elaine Lawrence }\end{array}$ & $\begin{array}{l}\text { Smart homecare system for } \\
\text { health tele-monitoring }\end{array}$ & $\begin{array}{l}\text { Describes } \\
\text { prototype }\end{array}$ & $\begin{array}{l}\text { Sistem yang dibuat } \\
\text { sangat bermanfaat } \\
\text { bagi perawatan } \\
\text { lasian dirumah serta } \\
\text { menguntungkan } \\
\text { bagi pihak } \\
\text { pemerintah }\end{array}$ \\
\hline 8. & $\begin{array}{l}\text { Rizkiyani Istifada, } \\
\text { Sukihananto, Muh. Ansoer } \\
\text { Laagu }\end{array}$ & $\begin{array}{l}\text { Pemanfaatan } \\
\text { telehealth pada perawat di } \\
\text { layanan homecare }\end{array}$ & Literature Review & $\begin{array}{l}\text { Telehealth di tatanan } \\
\text { homecare di } \\
\text { Indonesia perlu terus } \\
\text { dikembangkan }\end{array}$ \\
\hline
\end{tabular}


Dinamika Kesehatan Jurnal Kebidanan dan Keperawatan Vol 10 No. 1 Juli 2019 (ISSN: 2086-3454 EISSN: 2549-4058)

url: http://ojs.dinamikakesehatan.unism.ac.id DOI : https://doi.org/10.33859/dksm.v10i1

Pemanfaatan Teknologi Informasi Berbasis Internet Terhadap Perkembangan Home Care di Indonesia

\begin{tabular}{|c|c|c|c|c|}
\hline & & & & $\begin{array}{l}\text { dengan komitmen } \\
\text { dari semua pihak }\end{array}$ \\
\hline 9. & $\begin{array}{l}\text { Rr. Tutik Sri Hariyati, } \\
\text { Junaiti Sahar }\end{array}$ & $\begin{array}{l}\text { Perception of nursing care for } \\
\text { cardiovascular cases, knowledge } \\
\text { on the telehealth and } \\
\text { telecardiology in Indonesia }\end{array}$ & Qualitative study & $\begin{array}{l}\text { Telenursing perlu } \\
\text { terus dikembangkan } \\
\text { dengan komitmen } \\
\text { dari perawat dan } \\
\text { dukungan dari } \\
\text { pemerintah }\end{array}$ \\
\hline 10. & $\begin{array}{l}\text { Val Jones, Richard Bults, } \\
\text { Dimitri Konstantas, Pieter } \\
\text { AM Vierhout }\end{array}$ & $\begin{array}{l}\text { Healthcare PANs: Personal Area } \\
\text { Networks for trauma care and } \\
\text { home care }\end{array}$ & $\begin{array}{l}\text { Evidance-based } \\
\text { research }\end{array}$ & $\begin{array}{l}\text { Sistem yang dibuat } \\
\text { dapat menjawab } \\
\text { kebutuhan akan } \\
\text { masalah kesehatan } \\
\text { di masa depan pada } \\
\text { kasus traumacare } \\
\text { dan homecare }\end{array}$ \\
\hline 11. & $\begin{array}{l}\text { Veronica } \\
\text { Jonathan Price, Maxine } \\
\text { Hardinge, } \\
\text { Tarassenko, } \\
\text { Farmer }\end{array}$ & $\begin{array}{l}\text { Using a mobile health } \\
\text { application to support self- } \\
\text { management in COPD }\end{array}$ & Qualitative study & $\begin{array}{l}\text { Telehealth } \\
\text { berkontribusi dalam } \\
\text { pelengkap tindakan } \\
\text { medis untuk } \\
\text { memandirikan } \\
\text { pasien }\end{array}$ \\
\hline 12. & $\begin{array}{l}\text { Yoyok Bekti Prasetyo, } \\
\text { Thontowi Djauhari, Sri } \\
\text { Sunaringsih Ika Wardjojo }\end{array}$ & $\begin{array}{l}\text { Potensi layanan homecare di RS } \\
\text { UMM didasarkan pada analisa } \\
\text { kasus penyakit, ekonomi, dan } \\
\text { sosial masyarakat }\end{array}$ & Observasional & $\begin{array}{lr}\text { Kasus terbanyak } \\
\text { yang memerlukan } \\
\text { homecare yaitu } \\
\text { perawatan luka } \\
\text { diabetik, perawatan } \\
\text { antenatal dan pasca } \\
\text { stroke }\end{array}$ \\
\hline 13. & Yuli Lestari, Ida Subardiah & $\begin{array}{l}\text { Telehealth: Elektronik housecall } \\
\text { system, solusi mengurangi biaya } \\
\text { perawatan kesehatan }\end{array}$ & Literature Review & $\begin{array}{l}\text { Telehealth memiliki } \\
\text { peran penting dalam } \\
\text { proses perawatan } \\
\text { transisis pasien }\end{array}$ \\
\hline
\end{tabular}

\section{Kajian Literatur}

Telehealth merupakan salah satu

bentuk pelayanan keperawatan dengan

memanfaatkan teknologi komunikasi.

Telehealth dapat memberikan pelayanan

kesehatan berupa perawatan pasien langsung

(video teleconference) dan perawatan

kesehatan lainnya, serta pendidikan kesehatan.

Mobile health (Mhealth) merupakan bentuk

perawatan kesehatan yang disediakan dengan

menggunakan aplikasi pada teknologi seluler, misal berbasis smartphone atau tablet, sedangkan Ehealth adalah istilah luas mencakup semua layanan kesehatan yang menggunakan teknologi informasi ataupun telekomunikasi. Baik itu Ehealth, Mhealth maupun telehealth merupakan bentuk pemberian pelayanan kesehatan dalam hal ini keperawatan jarak jauh antara perawat dan pasien (Olson and Thomas, 2017).

Berdasarkan hasil penelitian Istifada tahun 2017, mengatakan bahwa penerapan 
Dinamika Kesehatan Jurnal Kebidanan dan Keperawatan Vol 10 No. 1 Juli 2019 (ISSN: 2086-3454 EISSN: 2549-4058)

url: http://ojs.dinamikakesehatan.unism.ac.id DOI : https://doi.org/10.33859/dksm.v10i1

Pemanfaatan Teknologi Informasi Berbasis Internet Terhadap Perkembangan Home Care di Indonesia

telehealth di Indonesia saat ini belum banyak

di aplikasikan pada pelayanan home care

keperawatan. Maksudnya adalah pelayanan

home care di Indonesia masih didominasi

bentuk tradisional, yaitu perawat datang

berkunjung ke rumah pasien untuk

memberikan pelayanan keperawatan (Istifada,

2017). Hal ini juga sejalan dengan penelitian

Wiweko pada tahun 2016 yang menyatakan

bahwa perkembangan telehealth di Indonesia

masih berfokus pada pelayanan kuratif oleh

dokter seperti tele-ECG dan teleradiology

(Wiweko, Zesario and Agung, 2017). Namun,

hal ini tidak serta merta mengartikan bahwa

home care di Indonesia tidak sama sekali

memanfaatkan teknologi informasi. Saat ini

home care di Indonesia sedang berkembang

dengan memanfaatkan teknologi informasi

berbasis internet, walaupun kadang masih di

kombinasi dengan metode tradisional ataupun

kolaborasi dengan tindakan medis. Hal ini

terlihat dari hasil penelitian Nurwahidin dkk

tahun 2017, yang mengembangkan aplikasi

untuk penemuan lokasi pasien yang ingin

menggunakan jasa home care serta permintaan atau pemesanan layanan kesehatan (termasuk

keperawatan) yang dibutuhkan pasien melalui

aplikasi berbasis internet. Bentuk pelayanan

yang tersedia dalam aplikasi yang

dikembangkan oleh Nurwahidin dkk berupa

cek darah lengkap, cek gula darah, cek

kesehatan jantung (EKG), fisioterapi,

pemeriksaan kesehatan bayi, perawatan luka

diabetic, perawatan pasca operasi, pijat bayi,

dan pengukuran tekanan darah (Nurwahidin,

Lestari and Raharjo, 2016). Hariyati dan Sahar

dalam penelitian kualitatifnya (2012) terkait

persepsi dan pengetahuan perawat tentang

telehealth menunjukkan bahwa meskipun

perawat masih kurang familiar dengan

telehealth tetapi beberapa perawat mengatakan

bahwa kadang mereka melakukan konsultasi

dengan pasien via telepon atau fax yang dalam

hal ini juga menggunakan teknologi informasi

(Tutik, Hariyati and Sahar, 2012).

Hal ini merupakan tantangan bagi

dunia keperawatan Indonesia dalam

meningkatkan pemanfaatan teknologi

informasi di tatanan home care. Peningkatan

teknologi dalam kesehatan merupakan hal 
Dinamika Kesehatan Jurnal Kebidanan dan Keperawatan Vol 10 No. 1 Juli 2019 (ISSN: 2086-3454 EISSN: 2549-4058)

url: http://ojs.dinamikakesehatan.unism.ac.id DOI : https://doi.org/10.33859/dksm.v10i1

Pemanfaatan Teknologi Informasi Berbasis Internet Terhadap Perkembangan Home Care di Indonesia

yang telah banyak dikembangkan saat ini untuk meningkatkan kualitas kesehatan pasien. Perawat memiliki peran penting dalam perubahan bentuk pelayanan keperawatan dengan pemanfaatan teknologi informasi. Berdasarkan penelitian Kent et al (2018) bahwa perawat komunitas memiliki peranan yang sangat penting dalam kesinambungan perawatan pasien jarak jauh dirumah, yaitu dalam penelitian ini terdapat tiga intervensi yang dapat dilakukan oleh perawat dalam merawat pasiennya dengan memanfaatkan teknologi informasi, yaitu dokumentasi data kesehatan pasien secara digital yang dapat di akses di smartphone, proses perawatan dengan menggunakan foto digital (misal foto perkembangan proses penyembuhan luka), dan konsultasi tatap muka dengan video (SittonKent, Humphreys and Miller, 2018). Selain Kent et al, Farrar dalam penelitiannya pada tahun 2015 juga menunjukkan bahwa perawat mampu memberikan intervensi keperawatan dengan memanfaatkan teknologi informasi. Farrar mengatakan bahwa telehealth dapat digunakan oleh perawat sebagai solusi bagi pasien yang memiliki keterbatasn akses. Intervensi keperawatan dalam hal ini keperawatan jiwa yang dapat dilakukan dengan telehealth menurut Farrar berupa intervensi terapi modalitas jarak jauh, memantau kepatuhan minum obat pasien, menjadi sistem monitoring pada pasien dengan penyakit kronis, dan konsultasi tatap muka melalui aplikasi videoteleconference (Farrar, 2015).

Di luar negeri sekarang pemanfaatan teknologi informasi khususnya berbasis internet terus berkembang untuk meningkatkan kualitas kesehatan pasien yang berada di rumah dengan menggunakan sensorsensor yang lebih mutakhir. Aplikasi dengan tambahan alat-alat sensor yang dapat memantau pasien dirumah sama seperti memantau pasien saat dirawat di rumah sakit dengan menggunakan sensor monitoring audio atau visual, serta sensor yang dapat memantau tanda-tanda fisiologis pasien yang dapat diletakkan dilingkungan pasien bahkan di tubuh pasien langsung. Hal ini biasanya sangat bermanfaat bagi pasien yang lebih merasa 
Dinamika Kesehatan Jurnal Kebidanan dan Keperawatan Vol 10 No. 1 Juli 2019 (ISSN: 2086-3454 EISSN: 2549-4058)

url: http://ojs.dinamikakesehatan.unism.ac.id DOI : https://doi.org/10.33859/dksm.v10i1

Pemanfaatan Teknologi Informasi Berbasis Internet Terhadap Perkembangan Home Care di Indonesia

nyaman menjalani perawatan di rumah dalam

lingkungan keluarganya (Jones et al., 2001;

Leijdekkers, Gay and Lawrence, 2007).

Penerapan pelayanan kesehatan

berbasis teknologi informasi juga memiliki

hambatan dalam pelaksanaannya. Dalam

penelitiannya Willams et al (2014) menggali

pendapat pasien yang menggunakan Mhealth

dalam proses perawatannya dirumah dengan

penyakit $C O P D$, dan menyatakan bahwa

hambatan yang dirasakan yaitu kesulitan

dalam penggunaan smartphone atau tablet atau

leptop yang dipengaruhi oleh pengalaman

masing-masing orang. Dalam hal ini

pengalaman yang dimaksud adalah alat

tersebut bukan merupakan alat yang digunakan

sehari-hari oleh beberapa orang. Selain itu

sebagian pasien merasa dengan perawatan

jarak jauh, mereka seperti terabaikan, sehingga

menurunkan motivasi bagi pasien untuk

menggunakan pelayanan kesehatan berbasis

teknologi informasi (Williams et al., 2014).

Berdasarkan hasil penelitian yang

dilakukan Daniel et al tahun 2013 mengatakan

bahwa perubahan keperawatan dari ilmu keperawatan kontemporer menjadi nursing informatics memiliki pengaruh yang sangat besar bagi dunia keperawatan. Nursing informatics yang merupakan perpaduan antara ilmu keperawatan, ilmu informatika dan ilmu computer dapat meningkatkan kualitas keperawatan baik dalam bidang keperawatan klinik, administrasi keperawatan, pendidikan dan penelitian. Perlu adanya perubahan besarbesaran yang dilakukan secara serempak dalam dunia keperawatan agar nursing informatics ini dapat terlaksana dengan baik (Daniel, 2013). Hal serupa juga dinyatakan Hariyati dan Sahar (2012) dalam penelitiannya yang menyebutkan bahwa dalam penerapan telenursing di Indonesia banyak persiapan yang harus dilakukan, termasuk sumber daya manusia, infrastruktur, regulasi dan juga sistem sosialisasi (Tutik, Hariyati and Sahar, 2012). Hal ini sejalan dengan Rencana Strategis Kementerian Kesehatan tahun 20152019 yang menyatakan bahwa dalam peningkatan pelayanan kesehatan berbasis teknologi informasi, pemerintah dan Kementerian Kesehatan akan mengalokasikan 
Dinamika Kesehatan Jurnal Kebidanan dan Keperawatan Vol 10 No. 1 Juli 2019 (ISSN: 2086-3454 EISSN: 2549-4058)

url: http://ojs.dinamikakesehatan.unism.ac.id DOI : https://doi.org/10.33859/dksm.v10i1

Pemanfaatan Teknologi Informasi Berbasis Internet Terhadap Perkembangan Home Care di Indonesia

dana sebesar $50 \%$ untuk penyediaan jaringan

data untuk akses Ehealth (Kementerian

Kesehatan Republik Indonesia, 2015). Adanya

dukungan dari pemerintah serta komitmen dari

keperawatan itu sendiri, maka hambatan dalam

pemanfaatan teknologi informasi dalam

pelayanan keperawatan di Indonesia akan

dapat diatasi, sehingga pelayanan keperawatan

terutama home care di Indonesia dapat

memanfaatkan semaksimal mungkin teknologi

informasi untuk meningkatkan kualitas

pelayanan keperawatan bagi pasien di rumah

serta berkontribusi dalam meningkatkan

derajat kesehatan bangsa.

\section{Kesimpulan}

Salahsatu indikator tercapainya

pembangunan nasional di Indonesia adalah tingkat derajat kesehatan masyarakatnya yang optimal. Salah satu strategi untuk mencapai tingkat derajat kesehatan masyarakat yang optimal adalah dengan pemanfaatan teknologi informasi berbasis internet pada tatanan pelayanan kesehatan, salah satu contohnya yaitu pemanfaatan teknologi informasi berbasis internet seperti telehealth maupun

Mhealh dalam home care. Hal ini sangat cocok

dengan geografis Indonesia yang terdiri dari kepulauan, dimana masih banyak masyarakat yang tinggal jauh dari fasilitas kesehatan atau permasalahan akses. Keperawatan merupakan salah satu profesi yang memiliki peran penting dalam proses peningkatan status kesehatan masyarakat. Dengan komitmen dari pemerintah dalam pengembangan dan peningkatan infrastruktur untuk pemanfaatan teknologi informasi kesehatan berbasis internet, dan peran serta keperawatan dalam pelaksanaannya, maka masalah kesehatan bagi masyarakat yang jauh dari fasilitas kesehatan atau yang memerlukan perawatan di rumah dapat terpecahkan, sehingga dapat mengotimalkan derajat kesehatan bangsa.

Pelayanan kesehatan dalam era global ini akan terus berkembang seiring dengan berkembanganya terknologi informasi, tidak terkecuali dalam dunia keperawatan. Keperawatan harus mengembangkan kiprahnya dalam pelayanan kesehatan serta berkontribusi untuk meningkatkan kesehatan 
Dinamika Kesehatan Jurnal Kebidanan dan Keperawatan Vol 10 No. 1 Juli 2019 (ISSN: 2086-3454 EISSN: 2549-4058)

url: http://ojs.dinamikakesehatan.unism.ac.id DOI : https://doi.org/10.33859/dksm.v10i1

Pemanfaatan Teknologi Informasi Berbasis Internet Terhadap Perkembangan Home Care di Indonesia

masyarakat. Salah satunya dengan

care. Nursing Current 5(1): 51-61.

memanfaatkan teknologi informasi berbasis

internet seperti telehealth atau Mhealth dalam

intervensi keperawatan yang diberikan,

contohnya dalam tatanan home care.

Peningkatan pengetahuan perawat mengenai

telehealth atau Mhealth akan selaras dengan

meningkatnya kualitas pelayanan keperawatan

yang diberikan, sehingga derajat kesehatan

masyarakat yang optimal dapat tercapai.

\section{Ucapan Terimakasih}

Fakultas Ilmu Keperawatan Universitas

Indonesia

\section{Daftar Pustaka}

Buletin APJII. (2018). Survei APJII: Penetrasi Internet di Indonesia Capai 143 Juta Jiwa. Apjii Available at: https://apjii.or.id/downfile/file/BULETI NAPJIIEDISI22Maret2018.pdf.

Daniel O. 2013. Nursing informatics: A key to improving nursing practice in Nigeria. International Journal of Nursing and Midwifery 5(5): 90-98.

Farrar FC. 2015. Transforming home health nursing with telehealth technology. Nursing Clinics of North America. Elsevier Inc 50(2): 269-281.

Istifada R. 2017. Pemanfaatan teknologi telehealth pada perawat di layanan home

Jones VM. 2001. Healthcare PANs: Personal Area Networks for trauma care and home care. Fourth International Symposium on Wireless Personal Multimedia Communications (WPMC), Aalborg, Denmark, 3: 1369-1374.

Kementerian Kesehatan Republik Indonesia. 2015. Rencana Strategis Kementerian Kesehatan Tahun 2015-2019. Kementerian Kesehatan Tahun: 248.

Leijdekkers P, Gay V, and Lawrence E. 2007. Smart homecare system for health telemonitoring. 1 st International Conference on the Digital Society, ICDS 2007.

Lestari Y, and Subardiah I. 2017. Telehealth: elektronik housecall system, solusi mengurangi biaya perawatan kesehatan. Jurnal Keperawatan XIII(2): 244-248.

Nurwahidin A, Lestari U, and Raharjo S. 2016. Aplikasi mobile untuk layanan perawatan medis di rumah (studi kasus di rumah sakit bhayangkara polda DIY). Jurnal teknik informatika 3(2): 79-92.

Olson CA, and Thomas JF. 2017. Telehealth: No longer an idea for the future. Advances in Pediatrics 64(1): 347-370.

Prasetyo YB, Djauhari T, and Wardojo SSI. 2016. Potensi layanan homecare di rs umm didasarkan pada analisa kasus penyakit, ekonomi dan sosial masyarakat. ejournal.umm.ac.id 7: 7078.

RISKESDAS. 2013. Penyakit yang ditularkan melalui udara. Jakarta: Badan Penelitian dan Pengembangan Kesehatan Departemen Kesehatan Republik Indonesia, (Penyakit Menular): 103. 
Sitton-Kent L, Humphreys C, and Miller P. 2018. Supporting the spread of health technology in community services. British Journal of Community Nursing 23(3): 118-122.

Tutik R, Hariyati S, and Sahar J. 2012. Perceptions of nursing care for cardiovascular cases, knowledge on the telehealth and telecardiology in Indonesia. International Journal of Collaborative Research on Internal Medicine \& Public Health 4(2): 116128.

Williams V. 2014. Using a mobile health application to support self-management in COPD: A qualitative study. British Journal of General Practice 64(624): 392-400.

Wiweko B, Zesario A, and Agung PG. 2017. Overview the development of tele health and mobile health application in Indonesia. International Conference on Advanced Computer Science and Information Systems, ICACSIS 2016: 914. 